\section{A model for digital development of SMEs: an interaction-based approach}

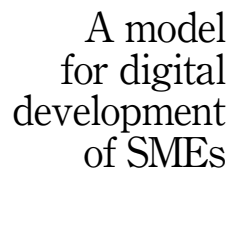

1049

Universita degli Studi della Tuscia, Viterbo, Italy

Stefano Za

University "G. d'Annunzio" Chieti-Pescara, Pescara, Italy, and

Eusebio Scornavacca

Merrick School of Business, University of Baltimore, Baltimore, Maryland, USA
Received 22 June 2020

\begin{abstract}
Purpose - E-business maturity models have been widely used to guide the process of digital transformation of business. However, these models have been criticized for their predominantly technocentric approach, which is poorly suited for SMEs. The purpose of this paper is to produce a holistic, nonlinear e-business development model for SMEs that takes into account the interactions of the organization in the pursuit of its business objectives.

Design/methodology/approach - Based on the literature review, this paper proposes a nonlinear digital development model for SMEs that factors in the interactions between digital technologies and organizational processes. The model is applied to three cases using a qualitative research approach.

Findings - The analysis of the cases demonstrates how the model recognizes that SMEs have an agile and flexible operating structure and reduces the role of technology in order to refocus the entrepreneurs on the relationship among business goals, organizational capabilities and communication requirements.

Practical implications - The proposed model helps the business owners to clarify and better understand what kind of interaction levels exist between the relevant actors in the pursuit of the firm's goals and to identify the best mix of digital and nondigital communication methods to support their work. It also assists policymakers to overcome technological bias when assessing the current state of play of e-business development in the SME universe and formulate actions that support the development of digitally oriented SMEs.

Originality/value - This paper proposes a novel, nonlinear, interaction-based development model for SMEs in order to complement previous technocentric models focusing mainly on a mechanist perspective of e-business maturity models.
\end{abstract}

Keywords E-Business, SMEs, Entrepreneurs, Maturity model, Digital technologies, Digital competences Paper type Research paper

\section{Introduction}

Digital business solutions are commonly adopted with the goal of improving firms' performance. Investments in technology represent often crucial decisions for enterprises, especially because they have the potential to transform organizational practices and impact profoundly on firm competitiveness (Grant et al., 2014). Specifically, investments in e-business adoption can result in tangible financial benefits (Johnston et al., 2007). These benefits can dramatically vary across regions, industries and, most importantly, firm size (Johnston et al., 2007). As a result, over the past couple of decades, the adoption of e-business by small and medium-sized enterprises (SMEs) has called the attention of a number of researchers interested in understanding the process of digital transformation of these organizations (Harridge-March 2004; Kim et al., 2013; Mazzarol, 2015; Taiminen and Karjaluoto, 2015). Overall, the literature in

(C) Paolo Depaoli, Stefano Za and Eusebio Scornavacca. Published by Emerald Publishing Limited. This article is published under the Creative Commons Attribution (CC BY 4.0) licence. Anyone may reproduce, distribute, translate and create derivative works of this article (for both commercial and noncommercial purposes), subject to full attribution to the original publication and authors. The full terms of this licence may be seen at http://creativecommons.org/licences/by/4.0/legalcode 
JSBED 27,7

1050

this area commonly shows that the implementation of e-business models is primarily customerdriven and smaller firms are commonly positioned at the very early stages of the adoption curve (Levenburg and Magal, 2005; Raymond and Bergeron, 2008).

Policymakers are paying growing attention to SMEs due to the important role they play in the development of the socioeconomic fabric of countries. For example, in March 2020, the European Commission has launched an SME strategy for sustainable and digital Europe. This has been driven by the fact that "only $17 \%$ of SMEs have successfully integrated digital technologies into their businesses" [1]. The European Commission aims at expanding "Digital Innovation Hubs across every region in Europe to empower SMEs to integrate digital innovations" (Raymond and Bergeron, 2008). This provides an important opportunity for scholars to create impact in the business community by proposing frameworks and models to help guide traditional SMEs to incorporate e-business into their operations and keep pace with the digital transformation of the business environment.

Over the years, academics have systematically advised practitioners to adopt maturity or stage models (both terms are used interchangeably in the literature) as roadmaps to evaluate future e-business investments (Johnston et al.,2007). The aim of these models is to give the firms a benchmark to measure the specific conditions of each step of their digital journey and to identify potential drivers and barriers for successful adoption (Rao et al., 2003). On the other hand, Alonso-Mendo et al. (2009) have questioned whether there is a "standard" sequential path to e-business adoption and if stage models are actually appropriate for SMEs. They pose that these models tend to lack support of empirical evidence and are too generic. In other words, they are not capable of responding to the diverse nature, structure and needs of SMEs (AlonsoMendo et al., 2009; Burgess, 2016; Levy and Powell, 2003). In addition, the body of literature in this field seems to be dominated by technocentric, linear approaches with a certain level of disregard to organizational capabilities and stakeholder interaction (Taylor and Murphy, 2004),

On the other hand, a few authors have examined the specificities of the adoption of e-business technologies by SMEs (Jahanshahi et al., 2013; Jones, 2013; Sanders and Galloway, 2013). For example, Thompson et al. (2013) show that many SMEs fail to exploit the benefits of wider information access and lower transaction that digital technologies afford. Nguyen and Waring (2013) found that customer relationship management adoption in SMEs is mainly affected by the entrepreneur innovativeness and employee involvement. In addition, Spinelli et al. (2013) noted that the absence of a clear strategic vision on the part of the entrepreneur and the lack of project management capabilities reduces the effectiveness of the investment of the SMEs. Finally, Durkin et al. (2013) concluded that even though social media is regarded by entrepreneurs as an essential tool for business growth, many SMEs fail to show evidence of a strategic approach to this matter. The authors point out that SMEs "operate in a way that is organic and informal and, as has been established, business is often developed through social contacts and through relationships mediated on a, personal, face-to-face basis." Their longitudinal study observed the emergence of a stage-free adoption pathway where a non-technocentric exploration of key issues "may determine a general degree of fit between social media adoption and the company's business model."

Differently from linear stage-oriented mainstream studies, the aforementioned studies seem to capture the composite nature of motivations of entrepreneurs when they explore and experiment some emerging digital solutions for their businesses alongside with consolidated, "traditional" methods and techniques. As Vial (2019) has pointed out, we still lack a comprehensive understanding of digital transformation even though "research has shown that technology itself is only part of the complex puzzle that must be solved for organizations to remain competitive in a digital world." (Vial, 2019, p. 118). As a result, the purpose of this paper is to produce a holistic, nonlinear e-business development model for SMEs that takes into account the interactions of the organization in the pursuit of its business objectives. 
The paper is structured as follows. After this introduction, the following section provides brief overview of the relevant literature regarding e-business maturity models and identifies strengths and weaknesses of models developed specifically for SMEs. This is followed by the conceptualization of the e-business development model for SMEs. Next, the model is applied to three cases. Finally, the paper rounds off with a discussion about the implications of the model and conclusions.

\section{E-business maturity models for SMEs in the literature}

A significant part of the literature on maturity models for e-business in SMEs poses that a successful implementation of e-business strategies is mainly related to the adoption of specific sets of digital technologies acquired in a specific sequence of steps. This body of literature can be clustered into three main categories (Depaoli and Za, 2013, 2017):

(1) Integration-aware models (such as Poon and Swatman, 1999; Martin and Matlay, 2001; Willcocks et al., 2000) mainly focus on the technological integration of internal and external systems. In these models, e-commerce is usually just one stage of e-business implementation. They have the aim of driving SMEs to use the Internet to integrate their internal and external systems (i.e. e-mail, web presence, supply chain integration, etc.). Their primary focus is on the adoption of technology, hence their basic value is the "capacity to offer a simple means of benchmarking ICT activity" (Beckinsale and Ram, 2006, p. 850).

(2) Customer-aware models (such as Chaston et al., 2001; Burgess et al., 2005). In this group, e-commerce is the only e-business operation of the firm. These models target predominantly customer-side communication and website development. The main aim is to provide guidelines to SMEs that want to exploit digital technology to enhance customer relations. The basic idea is to develop the firm's website to enable customers to select products and services, transmit purchase orders and make online payments. Unlike the integration-aware models, these models address exclusively e-commerce planning.

(3) Interaction-aware models (such as Rao et al., 2003; Daniel and Wilson, 2002; Magal et al., 2008). In this category, digital technology supports the interaction of multiple actors. E-business maturity models have the same key objective: to guide SMEs in the adoption of e-business applications that increase the efficiency and effectiveness of the firm's interaction with all its stakeholders, not just its customers. However, only few of them (such as Rao et al., 2003) include the organizational implications into the interaction perspective by acknowledging the existence of nontechnological drivers (e.g. the firm's commitment to leverage e-business to achieve its strategic goals) and barriers (e.g. costs, employee resistance to IS use).

Despite the varying number of stages, there is an overall consensus in the literature on how the SMEs adopt and develop e-business following an incremental approach (Ashworth, 2012; van de Ven and Poole, 1995). The first basic stage encompasses communicating via e-mail and displaying on a static website basic product and service information as well as contact details. This evolves all the way to a mature stage where the firm fully integrates the business website with the back-office systems (even though there is little empirical evidence that SMEs actually reach this final stage). The road from the first to the last stage is characterized by different levels of integration based on the progressive use of applications to communicate with customers and suppliers (e.g. searching for business information, buying and selling online and tracking website orders). The assumption is that the higher the stage reached, greater the advantages generated (e.g. reduction in communication costs, advertising and marketing for new business initiatives).

\section{A model for digital development of SMEs}


JSBED 27,7

1052

The three groups of models are also linked by a further commonality as each one calls for a sequential and progressive set of stages and indicates the specific technologies needed to implement the relative e-business functionalities. On the other hand, a growing number of authors question the appropriateness of e-business adoption stage models for SMEs (AlonsoMendo et al., 2009).

Martin and Matlay (2001) argue that the maturity model-based approach is misdirected and likely to fail in the SMS context. According to Zheng (2004), maturity models (e.g. that of Willcocks et al. (2000)) are more relevant and useful for large firms rather than SMEs. Indeed, such models do not take account of the variety and uniqueness of smaller firms. Taylor and Murphy (2004) argue that maturity models take exclusively a technological approach to the adoption of e-business. Moreover, these models often assume a sequential and progressive engagement with e-business information technology. Given the business and structural diversity of SMEs, there is a need for improving the understanding of how these firms recognize and develop business opportunities irrespectively of a particular set of technologies (Taylor and Murphy, 2004). Indeed, Levy et al. (2003) argue that e-business adoption cannot be modeled as a sequential process precisely because SMEs often have limited resources and must "pick and choose" to implemented only certain Internet applications in line with their business goals and priority. Also Zheng et al. (2004) argue that e-business adoption by SMEs depends mainly on their strategic focus, on the owner's knowledge of IT opportunities and on customer pressure, rather than on the requirements of a specific stage.

In summary, the fact that SMEs tend to adopt technology in a discontinuous way, taking a nonlinear, stage-by-stage progression path (Fillis et al., 2004), means it is necessary to build more representative models that assist in overcoming mechanistic approaches (Gerring, 2008).

\section{The theoretical underpinning for designing the proposed model}

In this section, we present the theoretical underpinnings used in the design of the proposed model. This is accomplished by exploring the relationship between organization, technology and interactions as well as by examining the skill set needed by an SME to develop and operate e-business.

\section{Technology, organization and interactions}

The literature review highlighted how stage models with a digital focus are unable to respond adequately to the e-business needs of an SME. In fact, technology is only in part a datum (exogenously set) and is dynamically defined by the intertwining of organizations, individuals and artifacts. The adoption of this perspective avoids both the technocentric and the human-centered viewpoints. These approaches can be misleading because the former sees technology as "black-boxes," while the latter underestimates its role. Orlikowski refers to this as the "entanglement in organizational practice" of technology: "Humans are constituted through relations of materiality - bodies, clothes, food, devices, tools, which, in turn, are produced through human practices." (Orlikowski, 2007, p. 1,438). The adoption of this approach seems to be particularly apt since "contemporary forms of technology and organizing are increasingly understood to be multiple, fluid, temporary, interconnected and dispersed" (Orlikowski, 2010, p. 137). Within this perspective, and for the purposes of this paper, we define interaction as the relations that bring together different practices within an organization to explore and respond to present and potential customers while pursuing the overall goals of the enterprise. These relations (e.g. commercial, contractual, technical) are based on various forms of communication, both analog and digital-enabled.

Specifically, e-business relations (interaction) include computer-mediated communication (CMC). It is useful here to note that, in the context of this paper, despite the development of the 
"synthetic worlds" deployed by organizations to support distributed collaboration (Orlikowski, 2010), a number of researchers remain skeptical and cautious when evaluating to what extent ICTs can be expected to mitigate "distance" since certain kinds of collaborative work require presence (Olson and Olson, 2000). It is known, however, that $\mathrm{CMC}$ interactions can reduce the psychological distance between people who work in geographically remote sites when face-to-face interactions are either too expensive or unfeasible (Oh et al., 2008; Schultze et al., 2008). Thus, the advent of new ICT sparks new opportunities for firms to interact, which, in turn, raises the question of what skills and capabilities are needed to effectively harness the new technological advances to an SME's traditional business operations. At the same time though, an excessive attention paid to technological aspects is to be avoided because it obscures the rich tissue of nondigital relations that innervate an organization in the pursuit of its goals.

\section{SMEs and the skill set needed to implement e-business}

Some of the issues inherent to technological determinism can be avoided by anchoring the adoption of digital artifacts in Orlikowski's approach whereby technology is to be considered as entangled in organizational practices. This means that communication practices will be reconfigured when people in an organization are engaged with a new set of ICTs (Orlikowski, 2007, p. 1441). This "reconfiguration" explains both (1) the caution of SMEs to jump into a fullfledged e-business and (2) the inadequacy of models based on technological stages. Indeed, a many small businesses use tailored communication channels with their clients and are reluctant to migrate to new channels that could require a new set of communication skills and tools on the part of suppliers, employees and customers. Orlikowski's framework shows also the inadequacy of technology-based stage models: in a given context and over time, new communication technologies generate expectations of generalized availability and accountability (Orlikowski, 2007, p. 1,442). If the analysis of "maturity" is confined to technological stages, the complexity and richness of nondigital communication skills and the process through which they are being challenged and reconfigured by digital technologies could result in an underestimation of the potential drawbacks and opportunities associated with the organizational change. Instead of a model based on a linear sequence of technological stages, we propose a model where an entrepreneur can choose to aim at a certain "level of interaction," which is aligned with the present mix of digital and nondigital "relational skillset." Once updated, it will enable the firm to better serve its present customers and to acquire new ones. Such alignment of the choice of the interaction level allows to govern the increase in expectations and costs associated to introducing new ICTs (Orlikowski, 2007). In terms of innovation theory, this interaction level approach meets the requirements of the "absorptive capacity" of a firm (Adams et al., 2006)

In order to build an e-business adoption model for SMEs, it is necessary to define a specific skill set required to evaluate and manage the performativity of the new digital technologies alongside the inherent organizational impacts and affordances.

The literature provides several definitions of ICT competence (Bassellier and Reich, 2001; Davern, 1996; Feeny and Willcocks, 1998). We have selected the holistic approach of Caldeira and Ward (2003) because, in defining the drivers of the overall organizational competence in ICT, they emphasize the importance of technical as well as managerial skills. Here we focus specifically on ICT-related skills.

Figure 1 shows some of the possible combinations of internal and external ICT competences versus internal and external ICT resources that an SME needs to consider when selecting a level of interaction. The position of an organization in the following framework is subject to a number of factors such as the industry in which the SME operates, firm size and the quality and level of sophistication of the communication.
A model for digital development of SMEs

1053 
JSBED

27,7

\section{4}

Figure 1.

External versus inhouse ICT resources and related competences

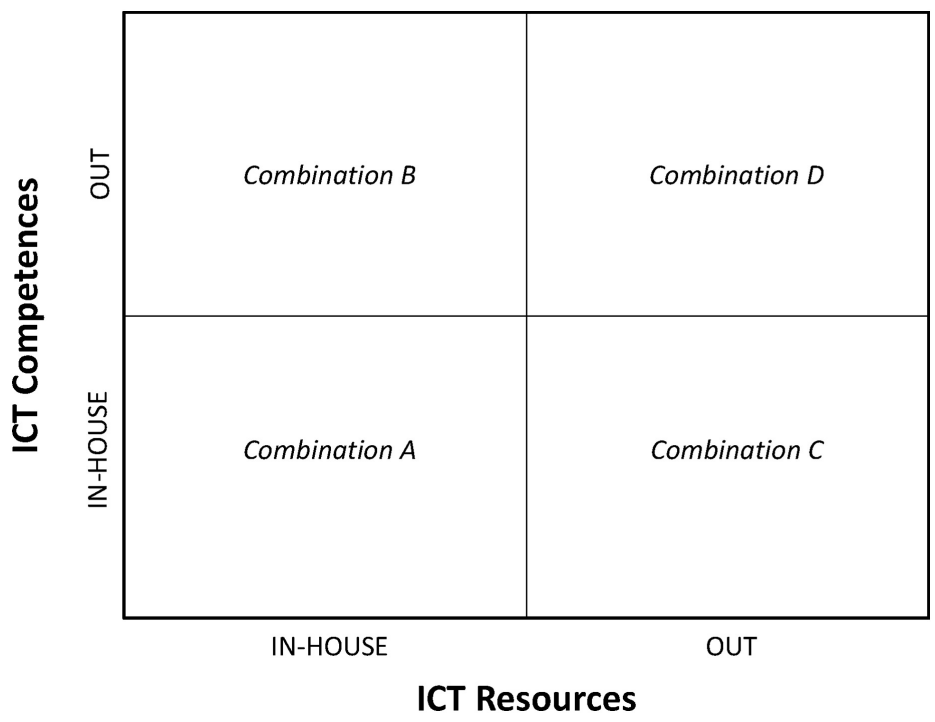

- Combination A: the firm's interaction levels tend to be either low or medium; the firm has the competences and technology needed to manage in-house hardware (personal computer, laptop, a few servers and basic network devices) and software (web browser, electronic mail, simple web editor or basic content management systems to create a website).

- Combination B: medium or high interaction levels denote this combination, in which external expertise (i.e. technology consultant) is paired with internal technology to enable the use of specific software to support. For example, the core activities that underpin customer interaction that require a high level of specialization can be acquired from dedicated service companies.

- Combination C: it is characterized by medium or high levels of interaction driven by internal competences and external technology (i.e. an Application Service Provider or "ASP") when high-performance infrastructure and systems are deployed to manage high volumes of traffic on web portals in order to deal with customer requests. Here, it is necessary to have a certain level of internal competences to effectively manage relations with the provider.

- Combination D: high and complete levels of interaction are what distinguish this combination. It calls for outsourcing both competences and $t$ technology to an external provider. Typically, this is the solution chosen for supply chain management systems. In this case, the firm still needs specific competences to initiate and manage the relationship with the outsourcer.

As outlined by these combinations, SMEs need to have good managerial capabilities as well as some knowledge of the state of play in the ICT market in order to choose the best e-business solutions for their needs. Perhaps, advisory services (government funded or not) could help to reduce the risk of SMEs falling into the imitation trap of e-business strategies (a kind of ICT isomorphism). 


\section{A nonlinear, interaction-based development model for e-business}

The proposed nonlinear development model (Figure 2) aims at supporting the entrepreneur to identify the different levels of interactions as well as the external and internal actors involved in the e-business design and implementation. It helps SME management to recognize which interaction levels are enabled by digital technologies and which ones could be improved by adopting specific digital solutions. One of the main strengthens of the model to the SME context is how it incorporates the interactions conducted by the organization.

The model is developed based on three underlying fundaments: (1) integrating interaction, (2) marrying technology to the organization and (3) newly defining e-business.

Integrating interaction refers to the need of integrating the digital and the nondigital modes of interaction used by individuals, teams and units of an organization to communicate internally and externally in the pursuit of the firm's business objectives. The concept of interaction is indeed relevant in organization theory that uses different approaches to shed light on the question of coordination and integration.

This paper uses the concept of processes of coordination proposed by Van De Ven et al. (1976) and Grandori and Soda (1995) as it seems particularly relevant for the context of SMEs. Van De Ven et al. (1976) further developed the work of Thompson (1967), tackling coordination mechanisms at the unit level and taking account of task uncertainty, interdependence as well as unit size. They pose that the use of group coordination (mutual adjustments based on scheduled or unscheduled meetings) is higher and more effective when the unit size is smaller and uncertainty and interdependence are higher. This type of situation is common in the SME context, where the average firm size is typically below ten employees and the workflow that is basically "undertaken jointly by unit personnel who diagnose, problem-solve and collaborate in order to complete the work" (Van De Ven et al., 1976, p. 325). Grandori and Soda (1995), in taking stock of network theories and frameworks, point out that "in order to maintain long-term cooperation, repeated sequential communications, decisions and negotiations must take place" (p. 194). Certainly, networks are of the utmost importance to complement the limited resources and capabilities of small firms and to enhance their scope of innovation (Gardet and Fraiha, 2012, p. 216). This emphasizes the crucial dimension of "interaction" in SMEs, the cornerstone for developing their relational capital via the exchanges (based on cooperation and trusting attitudes) with other organizations and
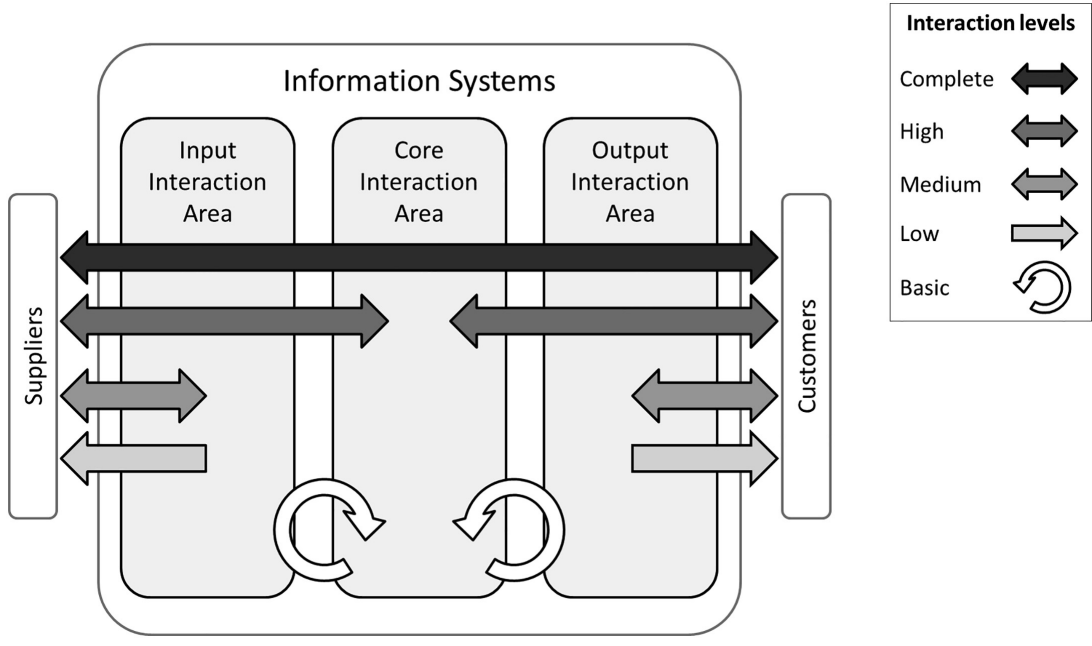

A model for digital development of SMEs

1055

Figure 2.

The interaction-based e-business development model for SMEs 
JSBED 27,7

1056

individuals (partners, suppliers, clients, institutions). Furthermore, the literature suggests that "relational capital" is a key aspect of industrial districts because it fosters collective learning (Capello, 1999) and innovation (Capello and Faggian, 2005; Molina-Morales and Martinez-Fernandez, 2006). Jansen et al. (2011) find that social capital (with its fundamental relational aspects) can positively affect the effectiveness of decision-making in small firms. Social network relationships are extremely relevant in open innovation contexts, particularly for spin-off SMEs (Padilla-Melendez et al., 2012). More generally, the specific nature of SME innovation is strictly correlated to their ability to respond to the changing needs of the market by forging close relationships with clients (Whitley, 2000), which entails a high level of client interaction.

Marrying technology to the organization. The model takes into consideration an integrated view of technology and organization. In other words, the existing business models can only be improved on if the focus is "redirected away from ICT as an end in itself and moved towards ICT as a means to an end, i.e. realizing business opportunities, generating profits and creating wealth" (Taylor and Murphy, 2004, p. 288).

Newly defining e-business. Building the model on the view that technology is not an end in itself but a complement to the business and organizational activities allows for a redefinition of e-business as the pursuit by the relevant internal and external actors of different levels of digitally supported interactions with the aim of exchanging information and knowledge significant to the objectives and operations of the business.

Based on the three underlying fundaments aforementioned, the operationalization of the model divides interaction into three fundamental areas and also categorizes the different levels of interaction intensity.

Kim et al. (2011) suggest that user interaction spaces can be classified as follows: (1) business-to-employee-to-business space (refers to the organization, its employees and its partners such as suppliers and distributors), (2) business-to-employee-to-consumer space (refers to the organization, employees and consumers), and (3) business-to-employee-toemployee space, which refers to the organization and its employees. Consequently, the model presents three key interaction areas as follows:

(1) "input interaction area" where the SME relates to individuals and organizations that supply intermediate goods and services;

(2) "output interaction area" that focus on the management of customer relations;

(3) "core interaction area" in which the firm's processes transform the relevant inputs into significant outputs.

The higher the number of actors and the degree of active participation, the more complex the technical and organizational implications become. Conversely, it is not unusual to find that one individual (i.e. the owner) manages all supplier and client activities of a small firm (i.e. both input and output interaction areas).

Taking into account potentially different levels of technically feasible and organizationally rewarding interaction involving diverse types of actors, the model emphasizes not only the number of actors and areas involved in the interaction processes, but also the intensity of their interactions. For example, a "low" level of interaction identifies a situation where only one party to the exchange has access to the information or knowledge and has no or little power to intervene on either the content or the method of interaction. At the other end of the scale, the "complete" level of interaction encompasses most of the relevant actors (employees, suppliers, customers, public administrations, etc.) that a firm has to collaborate with in the pursuit of its business goals. However, a "low" level must inevitably be preceded by a "basic" level of interaction to understand how the firm's internal levels of 
interaction do matter to e-business. These are prerequisite to more effective interaction with the external actors. Indeed, it is reasonable to presume that higher levels of interaction in information and knowledge exchanges with external actors can be achieved only when the internal actors have already reached an adequate level of interaction among themselves. The point here is that the internal actors must become familiarized to use techniques that improve social interaction and collaborative work, especially when ICTs are involved.

The five interaction levels of the proposed model do not represent a sequence, but the interrelated actions undertaken by a firm to implement e-business. The actions may be subject to change over time because entrepreneurs tend to change their objectives in line with the evolution of the business environment and new ICTs becoming available and/or affordable. The time factor and the nonsequential nature of the interaction levels of this nonlinear model better reflect how an SME customarily conducts its business. Typically, it maintains a flexible approach to adapt its level of interaction to the opportunities that arise with different partners.

Most stage models are mechanistic because they split the development of an SME's e-business into sequential steps. Instead, the proposed nonlinear model leaves room for the decision-makers to interpret a given situation based on the dynamic interplay of ICT and organizing activities. According to Levy and Powell (2003, p. 181), "SMEs are unlikely to follow a stages model" because entrepreneurs decide to "adopt technologies" on the basis of the expected business value rather than on a given maturity level. The "levels of interaction" of the proposed model are "markers" that enable an entrepreneur to make sense of prior experiences and/or to select the e-business solution appropriate for her organization and objectives. The five levels of interaction are described:

(1) Basic level: this level refers the interactions happening inside the boundaries of the firm in order to support internal business activities.

(2) Low level: minimal interaction with each actor communicating exclusively "one-way" in one of the three areas (input, core and output). Information is published and accessible to authorized individuals or organizations. Examples are website brochures for customers or online supplier order forms with transactions completed via traditional methods.

(3) Medium level: this level concerns a specific area of the firm, but the interaction is "twoway." Examples are: (1) interactive website functionalities for customers in the "output area" (e.g. chat, forum to exchange information on products or services); (2) intranet for firm employees; and (3) online procedures to exchange information on goods or services provided by suppliers in the "input area."

(4) High level: at this level there is a two-way interaction among subjects that operate in two different areas (core and input or core and output). Examples are: (1) an e-commerce portal used by customers to buy products or acquire services that requires the core area to complete the sale process; (2) the firm has software modules that allow suppliers to interact with the procurement office to finalize the purchasing process.

(5) Complete level: two-way interaction involving several actors and all areas. For example: (1) an e-commerce application that enables customers to buy personalized products and that creates an internal information flow while simultaneously generating an order to be transmitted to one or more suppliers; both the purchase and the sale are completed in the core area, while customers can track the progress of their order; (2) supply chain management systems when the firm is a link in the value chain.

\section{A model for digital development of SMEs}

1057 
JSBED

27,7

The model allows for different interaction levels in a single area as well as between different areas. Indeed, a high interaction level can involve two areas (e.g. when e-commerce functionalities require a high level of actor interactions only in the core and output areas), while the other areas remain at a low or a medium level.

Further, the model is not subject to a preconfigured set of technologies. It is not dominated by the IT infrastructure and software application management. Thus, the firm can adopt the kind of technology better suited to support a chosen level of interaction.

\section{Cases of e-business development by SMEs}

In order to test the applicability of the model, three cases of e-business development by SMEs were analyzed. The cases were identified based on the following criteria: (1) the firm had been in business for at least ten years and had a substantial business history; (2) its sales are distributed evenly among a significant number of clients (with respect to total revenue); (3) at least one of the three firms operates in the ICT industry; and 4) the SMEs employ ten or less people (inclusive of the business owner).

Three companies agreed to participate in the study. The business showcased in case Study 1 is a small real estate development company; in case Study 2, a small software house; and in case Study 3, a restaurant. This study is based on an exploratory multicase study methodology (Yin, 2009). Case research is appropriate for researching an area where theories are at formative stages and for emerging technologies. Case research is also appropriate for examining practice-based problems, since it allows a researcher to capture the knowledge of practitioners and use it to generate theory (Benbasat et al., 1987). The data collection was carried out primarily through semistructured face-to-face interviews with the business owners. They lasted between 75 and $90 \mathrm{~min}$. The interviews were recorded on audiotape and supplementary field notes were made during the interview. Some supplementary data was collected through supporting documents volunteered by the interview participants (Yin, 2009). The companies were given fictitious names in the paper for confidentiality purposes.

\section{Case study 1 - "constructa”}

"Constructa" is a small, family-owned firm that operates in urban development, in particular, residential and commercial building projects. It has been in business for 30 years. The founder and his two sons (the entrepreneurial group) are assisted by three full-time employees (secretary and two accountants) and five outsourced professionals (architects and surveyors).

In order to identify the three fundamental interaction areas of the business and the associated interaction levels, it was necessary to first map the firm's core activity workflow as follows:

(1) Preliminary investigation phase. Once the town planning office has approved an urban development project, a geographical site is identified. At this point, Constructa engages in an intense level of interaction with the relevant local government departments to obtain the legal permits. This normally entails a great deal of red tape. This long, drawn-out process is managed personally by the owners and assisted by the office staff.

(2) Design phase. The work of this phase is mandated to the outsourced professionals, also responsible for contacting and organizing a range of experts specialized in areas such as urban planning, geology, archaeology, architecture, structural design and 
safety management. In this phase, the project design and construction documents are prepared.

(3) Building phase. This is the phase in which the different contractors are selected and hired for each work domain (e.g. water, sanitation, electrical systems); the contractors are managed by the site manager under the supervision of an architect (usually the same person who was responsible for the design phase).

(4) Sales phase: property sales are managed by an external agency, which sometimes starts the sales campaign before the building work is completed to accommodate any buyers who wish to customize their new property.

The first critical factor for Constructa's success is the interaction with local government in the preliminary investigation phase. The second critical factor is the coordination of the outsourced professionals who manage the contractors during the next phases (in the input interaction area) and the sales agents (in the output interaction area). The interactions between Constructa's internal stakeholders (owners and staff) and external stakeholders (the town planning officers, outsourced professionals and sales agents) take place in the core interaction area.

The four core activity phases of Constructa's business operations define the levels of interaction that connect actors and the different interaction areas. These interactions can take place in a digital as well as analog format (e.g. phone and/or face-to-face meetings). In fact, the vast majority of the firm's communications and interactions are basically nondigital. As a result, the digitally supported level of interaction never rises above "medium" (Figure 3).

As indicated in Figure 3, Constructa uses e-mail across all three fundamental interaction areas (i.e. to exchange draft contracts or projects with suppliers, for internal staff and/or client correspondence). The output interaction area is where the sales agent interacts with the potential buyers. It uses primarily a website to showcase the property. The website provides contact information, the project's history, directions to the site location, property information, images and any other facilities that might be offered. The website is basically one-way interaction ("low" interaction level) even though potential buyers are given the option of sending the property agent their contact telephone number. Constructa does not believe a corporate website would add value to the business.

The core interaction area envisages the higher use of digital tools: an ad-hoc software application for accounting and a file-sharing system. More recently, a shared electronic

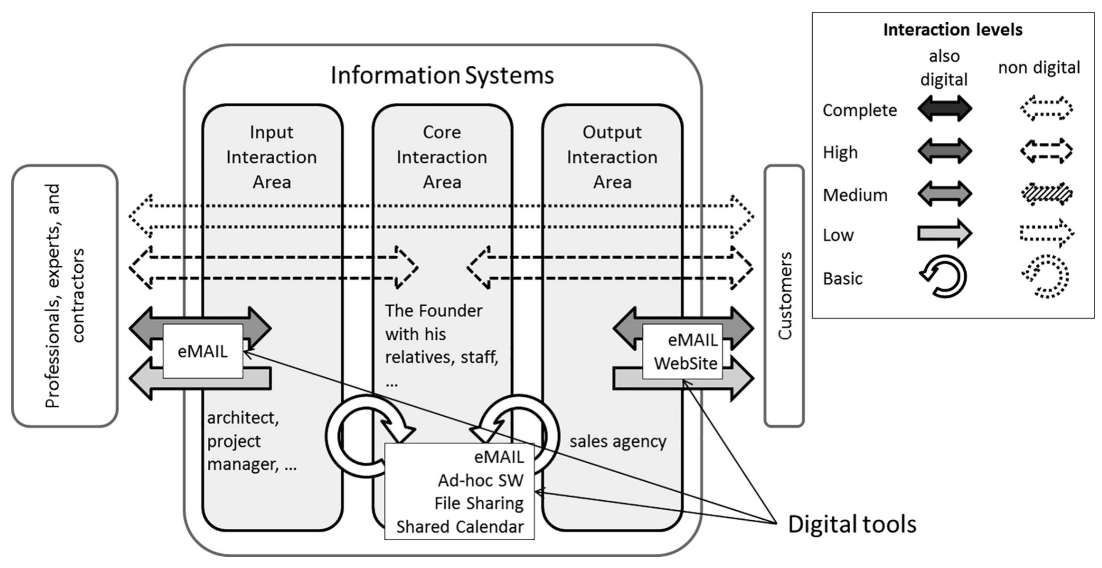

A model for digital development of SMEs

1059

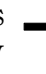


JSBED 27,7

1060 calendar was adopted by the entrepreneurial group and the outsourced professionals for appointments, meetings, deadlines and contact information. This adoption was driven by the need for timely information to coordinate activities effectively. Previously, the founder and main scheduler would sometimes forget to pass on relevant information, causing inefficiencies and some missed opportunities. It was therefore necessary to remedy this issue and the secretary is now responsible for getting his schedule and posting it on the electronic calendar.

Given that Constructa relies mostly on nondigital interaction, the use of paper still is important there. For example, during the building phase the contractors use a construction site ledger to record all the activities relative to the input interaction area. There is almost no direct interaction between the suppliers and the buyers. The "complete non-digital interaction level" is reached only when a building is sold prior to completion, making it necessary to outsource the buyer's customization requirements to a specific contractor.

The digitally enabled interaction is supported by simple tools (e.g. e-mail, accounting management tools, file sharing and office automation) and relies on the firms' internal digital competences for its use. On the other hand, external consultants are used for ICT administration, configuration and upgrade. The IT infrastructure (servers, PCs and other IT equipment) is located at corporate headquarters. Only the web server (for hosting the project websites) and the e-mail server are provided by an external ICT service provider. The model allowed the mapping of the company interaction identifying opportunities for digitally supported relations to smoothen collaboration, avoid conflicts and strengthen project visibility.

Case study 2 - "softer"

"Softer" provides ICT training and software development services. Launched in the early 2000s, its initial focus was on training (partner of Sun and then Oracle). After five years, Softer started to develop proprietary software applications (first for B2B, then for B2C) using the innovative technologies taught in its courses, with the dual aim of enhancing its teaching activities and of pursuing new business opportunities. In 2010, Softer decided to base its development activities and training on Apple, with a growing interest in mobile apps. Presently the firm employs a total of six people (developers and instructors) plus a part-time accountant and an accountancy consultant to prepare the financial statements (a "cloud" application developed internally serves both of them).

The interview concerned the owner who personally manages key client sales, leveraging his technical and teaching expertise. He assigns the smaller potential clients (especially for the mobile apps market) to five part-time sales agents paid on a commission basis. Two types of interactions take place in the output interaction area: (1) the owner's interaction with the key clients and sales agents (the latter use an e-calendar for their business appointments); (2) the instructors' interaction with the students. The former consists of face-to-face meetings, phone calls and e-mail correspondence; the latter work in the classrooms organized at the clients' premises. Products and services are showcased on the company's website and on the pages of the most visited social networks (e.g. Facebook, Google+). In the output interaction area (see Figure 3), the digitally supported interaction does not rise above the "medium" level, while the nondigital interaction hits the "complete" level only when the design and the clients of Softer's training courses create further opportunities for Apple.

The core interaction area is where the new training courses and the new software are developed. The traditional white board is the main driver of employees' interaction, on which these latter post different colored sticky notes with information on the matters discussed in the daily meetings; video conferences are used occasionally to bring agents or external colleagues into the discussion. The Agile approach taken by Softer means that the software it 
develops is organized by weekly objectives, so the firm perceives no need for a shared calendar or planner. The e-mail is used to track exchanges of information and two servers support software versioning and document and file sharing.

The employer is the main actor in the input interaction area, responsible for managing relations with Apple and other corporations that might be interested in a business agreement and hardware and software procurement, using the telephone and the e-mail or sometimes the internet. However, small orders for specific needs can be placed by the employees so long as the supplier is known and reliable.

As summarized in Figure 4, the Softer case study attests that, despite the firm having the appropriate ICT competences, the owner finds face-to-face interaction to be more effective than innovative cooperative work tools: its business aims often call for resolving installation, management and updating issues. Interestingly, during the interview, Softer's owner showed a proprietary mobile app the firm had developed specifically for restaurants marketed through its sales agents. The app enables the customer to view the seating areas of the restaurants that bought the app, choose a table and book it via the Internet. At the time of the interview, the mobile app had been adopted by about 70 restaurants across ten of Italy's major cities. Case Study 3 is based on the analysis of the e-business of one of those restaurants.

\section{Case study 3 - "bistrot"}

"Bistrot" is a small restaurant that has been run by the same two partners for 27 years. One partner is the chef (with one/two assistants) while the other manages the dining room and two serving staff (three at peak times). The interviewee was the latter partner. Bistrot is located in the city's historical center and can seat up to 60 customers in winter and about 100 in late spring and summer when the garden is open. The cuisine is typical to Northern Italy and is based on the traditional recipes of the chef's home town. The eatery adopts a friendly style of interaction to relate to its customers, hence the partner and dining room manager first describes the variety of dishes on the menu and the restaurant's philosophy of serving only authentic fare and then leaves the waiter to key in the order on a handheld device and transmits it to the kitchen. The restaurant website gives its location and a description of the cuisine in Italian and English and the customer can use a smartphone app to make a reservation. The app displays the restaurant's dining arrangements and indicates the vacant tables and number of seats, alerts the partner via his smartphone when a customer makes a

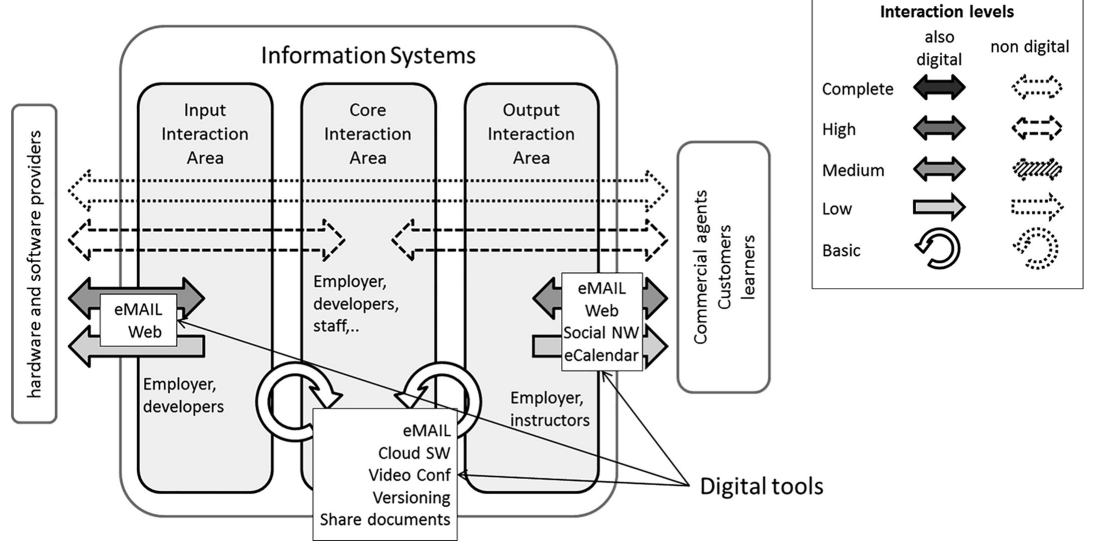

Figure 4.

Softer - digital and nondigital interaction levels 
JSBED 27,7

1062

booking and is then used to confirm the table reservation and to update the seating plan. The respondent explained how useful the app is during the tourist season, when travelers from different countries often choose restaurants after checking the reviews posted by the specialized tourism and travel websites (e.g. Trip Advisor), with the app crossing the language barriers that often crop up on the phone. Even Bistrot's Italian clientele choose the app over the telephone (although this remains a firm favorite) when they are part of a group that wants to decide the booking together instead of leaving just one person to call the restaurant.

Figure 5 shows how the interaction of the chef with suppliers in the input interaction area is nondigital, although the level qualifies as "medium" due to the frequent questions and suggested menu options. Further, the core interaction area and the output interaction area are connected by "digital high" interaction levels due to the combined presence of the personal and the digital (handheld devices) and the fact that the booking app enables communication with non-Italian-speaking customers or potential customers.

\section{Positioning the digital skill set for the three cases}

Based on the framework presented in Figure 1 (ICT resources and competences), Figure 6 presents an analysis of the three cases described earlier. This matrix can further support the entrepreneur in evaluating the digitalization actions regarding a specific level of interaction. Indeed, analyzing the three cases, it is possible to recognize three different approaches in respect to where IT competences and resources are positioned in each organization. Each approach depended on the business sector that the organization operates and how much the entrepreneur perceives digital technologies as essential to their core business activities. Bistrot is the case in which IT competences were not considered necessary for carrying on the firm's main activities. Digital devices are exclusively used for interacting with customers and receiving information about the reservations. In this case, the main digital resources are located externally (in the cloud) and managed by an IT consultant or a software house. For this reason, the case Bistro is an example of the combination D. An opposite attitude is illustrated by the Softer case, a software house where digital resources are located partially inside and partially outside the organization (in the cloud). The core IT competences are completely internal, and they are vital for core activities such as the design and development of IT solutions. For this reason, Softer is an example of the combination A. The case Costructa

Figure 5.

Bistrot - digital and nondigital interaction levels

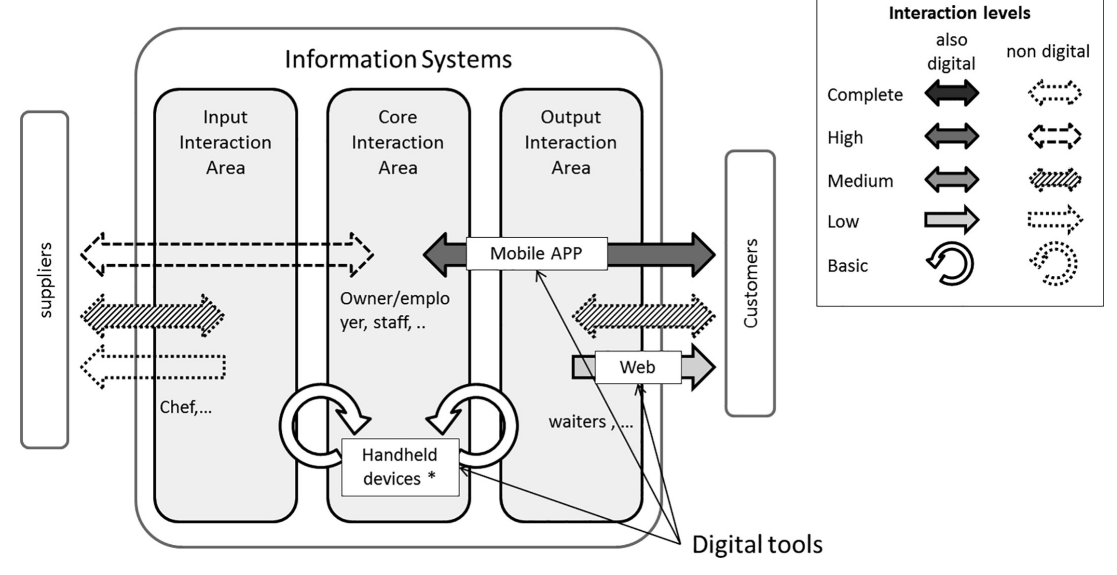




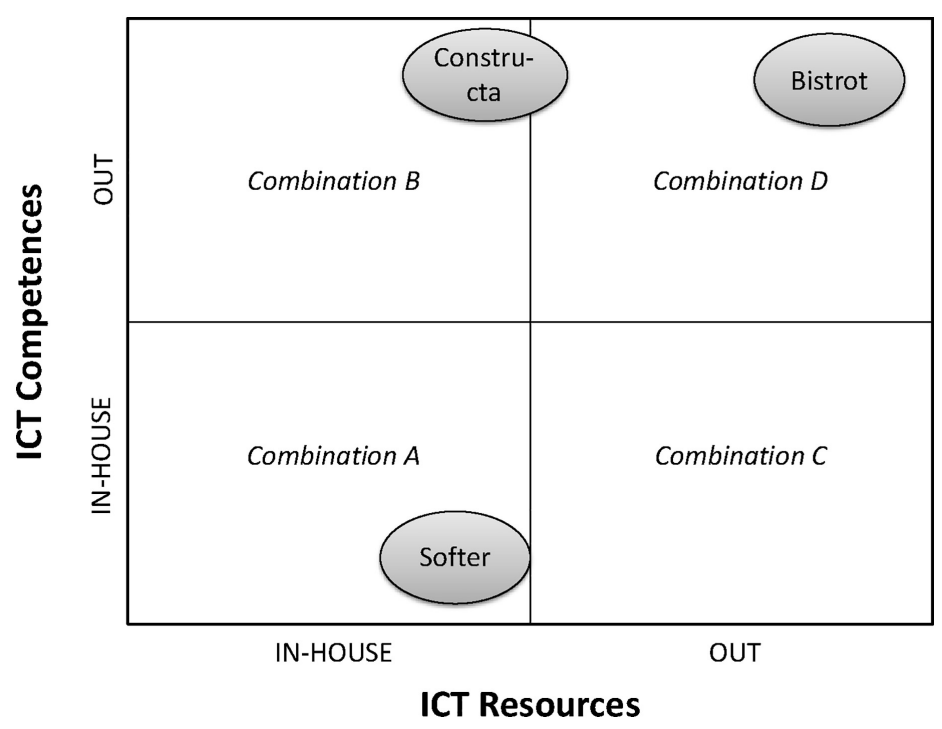

A model for digital development of SMEs

1063

Figure 6.

Analysis of the three cases in relation to ICT resources and competences

represents a hybrid configuration, where the IT competences for managing IT resources are completely outsourced (as in Bistrot). On the other hand, similarly to Softer, digital resources are located partially inside and partially outside the organization. For this reason, Constructa is an example of the combination B.

\section{Discussion and conclusions}

This paper proposes a nonlinear, interaction-based development model for SMEs in order to complement previous technocentric models focusing mainly on a mechanist perspective of e-business maturity models. It draws on Orlikowski's work $(2007,2010)$ to define possible levels of digital and nondigital interaction among different practices in the pursuit of the goals of the enterprise. E-business is conceived as a multilevel ICT-supported interaction among the relevant (internal and external) actors of an SME. With its interpretive and supportive design, the proposed nonlinear model aims at guiding business owners and advisors in implementing an SME e-business strategy that effectively meets business needs.

Even though it is developed to better support the process of digitization of smaller firms, the proposed model is actually an enterprise model for SMEs based on interaction levels. Here, its usefulness in complementing other approaches is briefly shown by reference to the work of Osterwalder and Pigneur (2011) and to the viable system model literature (Beer, 1984; Hoverstadt and Ward, 2010). Osterwalder and Pigneur (2011) are mostly concerned with the identification of the key components of a business model, which constitute their business model canvas, and with the iterative process that allows for an appropriate model to be built. They warn entrepreneurs not to stop at their initial business model but to "iteratively adapting [it] in response to customer feedback" (p. 71) - which indeed underlines the role of the "output interaction area" in this paper. Of the complex architecture and evolution of systems that are viable, that is "capable of independent existence" explained by Beer (1984, p. 7), one basic rule is of interest here: the way a system, with its subsystems, interacts with its environment is key to his viability (paraphrased, Beer, 1984, p. 14). Within the systemic approach, Hoverstad and Ward (2010) highlight the interactive and generative character of 
JSBED 27,7

1064

organizations: "organizations have multiple purposes which are emergent properties of the system. For us to understand how the organization works as a system, we need to be able to model multiple purposes, how these interact and how they have been generated by the system, are being generated currently and are likely to be created in the future." (p. 4). In this paper, the proposed model is nonlinear exactly because it acknowledges the fact that the interactions of the firm both within itself, among its subsystems and with its external environment generate emerging needs and purposes. These may produce novel levels of interaction and digitization. Finally, Hoverstad and Ward (Hoverstadt and Ward, 2010, p. 5), drawing on the work of Humberto Maturana (2002) on structural coupling, underscore that the identity itself of a system (e. g. an individual, a firm) can be viewed through the relationships it engages with other entities: "When one system is an important part of the environment of another system and vice versa the second system forms an environmental element for the first, clearly when one system changes the other will tend to change too.”... "The definition of identity then is by reference to the key relationships the system has with its environment." In the model proposed in this paper, the importance of mutual influence among actors (actually "systems") is in fact acknowledged in the subsection "integrating interaction intensity" depicting four possible interaction levels (low, medium, high and complete) in the relationships engaged by an SME.

In sum, the three cases show how the model downsizes the role of technology to refocus the decision-makers on the relationship between business aims, organizational capabilities and communication requirements, a highly important issue for an SME that operates an agile and flexible operating structure. The proposed model helps the business owners to clarify and better understand what kind of interaction levels exist between the relevant actors in the pursuit of the firm's goals and to identify the best mix of digital and nondigital communication methods to support their work. In other words, the model redirects the focus of the entrepreneur from the search of a technology per se to a more meaningful question: "What business and organizational requirements are needed to build a more effective and efficient relationship (i.e. an appropriate level of interaction) with my clients and suppliers? Consequently, what are the critical ICT enabling features and competences?" Indeed, the cases show that familiarity with IT is not decisive in adopting (or in extending the use of) e-business: Softer resorts less than Bistrot to digital support. The three small organizations seem to be "interaction driven" rather than "digital technology driven" in their approach to e-business.

This model can be useful to policymakers to sidestep the technological bias when assessing the current state of play of e-business development in the SME universe and, hence, to aid the formulation of the actions needed to support the SMEs in developing a digitally oriented business. Finally, as further step, it could be interesting to investigate how the levels of digital interaction depicted in the proposed model (Figure 1) are related to variables such as the industry in which the SME operates and the firm size.

\section{Note}

1. Communication from The Commission To The European Parliament, The Council, The European Economic And Social Committee And The Committee Of The Regions: An SME Strategy for a sustainable and digital Europe, COM/2020/103 final, p. 3.

\section{References}

Adams, R., Bessant, J. and Phelps, R. (2006), "Innovation management measurement: a review", International Journal of Management Reviews, Vol. 8 No. 1, pp. 21-47, doi: 10.1111/j.1468-2370. 2006.00119.x. 
Alonso-Mendo, F., Fitzgerald, G. and Frias-Martinez, E. (2009), "Understanding web site redesigns in small- and medium-sized enterprises (SMEs): a U.K.-based study on the applicability of e-commerce Stage Models", European Journal of Information Systems, Vol. 18 No. 3, pp. 264-279.

Ashworth, C.J. (2012), "Marketing and organisational development in e-SMEs: understanding survival and sustainability in growth-oriented and comfort-zone pure-play enterprises in the fashion retail industry", International Entrepreneurship and Management Journal, Vol. 8 No. 2, pp. 165-201, doi: 10.1007/s11365-011-0171-6.

Bassellier, G. and Reich, B. (2001), "Information technology competence of business managers: a definition and research model", Journal of Management Information Systems, Vol. 17 No. 4, pp. 159-182.

Beckinsale, M. and Ram, M. (2006), "Delivering ICT to ethnic minority businesses: an action-research approach", Environment and Planning C: Government and Policy, Vol. 24 No. 6, pp. 847-867.

Beer, S. (1984), "The viable system model: its provenance, development, methodology and pathology", Journal of the Operational Research Society, Vol. 35 No. 1, pp. 7-25, doi: 10.1057/jors.1984.2.

Benbasat, I., Goldstein, D.K. and Mead, M. (1987), "The case research strategy in studies of information systems", MIS Quarterly, Vol. 11 No. 3, p. 369, doi: 10.2307/248684.

Burgess, S. (2016), "Representing small business web presence content: the web presence pyramid model", European Journal of Information Systems, Vol. 25 No. 2, pp. 110-130, doi: 10.1057/ejis. 2015.4 .

Burgess, S., Sellitto, C. and Wenn, A. (2005), "Maturity in the websites of Australian wineries: a study of varying website content", International Journal of Electronic Business, Vol. 3 No. 5, pp. $473-490$.

Caldeira, M.M. and Ward, J.M. (2003), "Using resource-based theory to interpret the successful adoption and use of information systems and technology in manufacturing small and mediumsized enterprises", European Journal of Information Systems, Vol. 12 No. 2, pp. 127-141.

Capello, R. (1999), "Spatial transfer of knowledge in high technology milieux: learning versus collective learning processes", Regional Studies, Vol. 33 No. 4, pp. 353-365.

Capello, R. and Faggian, A. (2005), "Collective learning and relational capital in local innovation processes”, Regional Studies, Vol. 39 No. 1, pp. 75-87.

Chaston, I., Badger, B., Mangles, T. and Sadler-Smith, E. (2001), "The internet and e-commerce: an opportunity to examine organisational learning in progress in small manufacturing firms?", International Small Business Journal, Vol. 19 No. 2, pp. 13-30.

Daniel, E. and Wilson, H. (2002), “Adoption of e-commerce by SMEs in the UK”, International Small Business Journal, Vol. 20 No. 3, pp. 253-270.

Davern, M.J. (1996), "When good fit is bad: the dynamics of perceived fit", Seventeenth International Conference on Information Systems - ICIS1996 proceedings, pp. 112-121.

Depaoli, P. and Za, S. (2013), "Towards the redesign of e-business maturity models for SMEs", in Baskerville, R., De Marco, M. and Spagnoletti, P. (Eds), Designing Organizational Systems, Springer, Berlin Heidelberg, pp. 285-300, doi: 10.1007/978-3-642-33371-2_15.

Depaoli, P. and Za, S. (2017), "SME e-business development: an interaction based approach", Proceedings of the 25th European Conference on Information Systems, ECIS 2017, Guimarães, Portugal, June 5-10.

Durkin, M., McGowan, P. and McKeown, N. (2013), "Exploring social media adoption in small to medium-sized enterprises in Ireland", Journal of Small Business and Enterprise Development, Vol. 20 No. 4, pp. 716-734, doi: 10.1108/JSBED-08-2012-0094.

Feeny, D.F. and Willcocks, L.P. (1998), "Core IS capabilities for exploiting information technology", Sloan Management Review, Vol. 39 No. 3, pp. 9-21.

Fillis, I., Johansson, U. and Wagner, B. (2004), "A qualitative investigation of smaller firm e-business development”, Journal of Small Business and Enterprise Development, Vol. 11 No. 3, pp. 349-361.
A model for digital development of SMEs 
JSBED 27,7

Gardet, E. and Fraiha, S. (2012), "Coordination modes established by the hub firm of an innovation network: the case of an SME bearer", Journal of Small Business Management, Vol. 50 No. 2, pp. 216-238.

Gerring, J. (2008), "Review article: the mechanismic worldview: thinking inside the box", British Journal of Political Science, Vol. 38 No. 1, pp. 161-179, doi: 10.1017/S0007123408000082.

Grandori, A. and Soda, G. (1995), "Inter-firm networks: antecedents, mechanisms and forms", Organization Studies, Vol. 16 No. 2, pp. 183-214.

Grant, K., Edgar, D., Sukumar, A. and Meyer, M. (2014), "Risky business: perceptions of e-business risk by UK small and medium sized enterprises (SMEs)", International Journal of Information Management, Vol. 34 No. 2, pp. 99-122, doi: 10.1016/j.ijinfomgt.2013.11.001.

Harridge-March, S. (2004), "Electronic marketing, the new kid on the block", Marketing Intelligence and Planning, Vol. 22 No. 3, pp. 297-309, doi: 10.1108/02634500410536885.

Hoverstadt, P. and Ward, A. (2010), "Defining identity by structural coupling in VSM practice”, UKSS International Conference, Oxford.

Jahanshahi, A.A., Zhang, S.X. and Brem, A. (2013), "E-commerce for SMEs: empirical insights from three countries", Journal of Small Business and Enterprise Development, Vol. 20 No. 4, pp. 849-865, doi: 10.1108/JSBED-03-2012-0039.

Jansen, R.J.G., Curseu, P.L., Vermeulen, P.A.M., Geurts, J.L.A. and Gibcus, P. (2011), "Information processing and strategic decision-making in small and medium-sized enterprises: the role of human and social capital in attaining decision effectiveness", International Small Business Journal, Vol. 31 No. 2, pp. 192-216.

Johnston, D.A., Wade, M. and Mcclean, R. (2007), "Does e-business matter to SMEs? A comparison of the financial impacts of internet north American SMEs", Journal of Small Business Management, Vol. 45 No. 3, pp. 354-361.

Jones, D.P. (2013), "E-business and the SME: international perspectives of deployment", Journal of Small Business and Enterprise Development, Vol. 20 No. 4, doi: 10.1108/JSBED-08-2013-0112.

Kim, H.D., Lee, I. and Lee, C.K. (2011), "Building Web 2.0 enterprises: a study of small and medium enterprises in the United States", International Small Business Journal, Vol. 31 No. 2, pp. 156-174.

Kim, H.D., Lee, I. and Lee, C.K. (2013), "Building Web 2.0 enterprises: a study of small and medium enterprises in the United States", International Small Business Journal, Vol. 31 No. 2, pp. 156-174, doi: 10.1177/0266242611409785.

Levenburg, N.M. and Magal, S.R. (2005), "Applying importance-performance analysis to evaluate E-business strategies among small firms”, E-service Journal, pp. 29-48, January 2005.

Levy, M. and Powell, P. (2003), "Exploring SME internet adoption: towards a contingent model", Electronic Markets, Vol. 13 No. 2, pp. 173-181.

Magal, S.R., Koslage, P. and Levenburg, N.M. (2008), "Towards a stage model for E-business adoption among SMEs: preliminary results for manufacturing and service firms", AMCIS 2008 Proceedings.

Martin, L.M. and Matlay, H. (2001), “"Blanket” approaches to promoting ICT in small firms: some lessons from the DTI ladder adoption model in the UK", Internet Research, Vol. 11 No. 5, pp. 399-410.

Maturana, H. (2002), "Autopoiesis, Structural Coupling and Cognition: a history of these and other notions in the biology of cognition", Cybernetics and Human Knowing, Vol. 9 Nos 3-4, pp. 5-34.

Mazzarol, T. (2015), "SMEs engagement with e-commerce, e-business and e-marketing", Small Enterprise Research, Vol. 22 No. 1, pp. 79-90, doi: 10.1080/13215906.2015.1018400.

Molina-Morales, F.X. and Martinez-Fernandez, M.T. (2006), "Industrial districts: something more than a neighborhood”, Entrepreneurship and Regional Development, Vol. 18 November, pp. 503-524. 
Nguyen, T.H. and Waring, T.S. (2013), "The adoption of customer relationship management (CRM) technology in SMEs", Journal of Small Business and Enterprise Development, Vol. 20 No. 4, pp. 824-848, doi: 10.1108/JSBED-01-2012-0013.

Oh, H., Curley, S.P. and Subramani, M.R. (2008), "The Death of Distance?: the influence of computer mediated communication on perceptions of distance", Twenty Ninth International Conference on Information Systems - ICIS 2008 proceedings, Paris.

Olson, G.M. and Olson, J.S. (2000), "Distance matters”, Human-Computer Interaction, Vol. 15 No. 2, pp. 139-178.

Orlikowski, W.J. (2007), "Sociomaterial practices: exploring technology at work", Organization Studies, Vol. 28 No. 9, pp. 1435-1448.

Orlikowski, W.J. (2010), "The sociomateriality of organisational life: considering technology in management research", Cambridge Journal of Economics, Vol. 34 No. 1, pp. 125-141.

Osterwalder, A. and Pigneur, Y. (2011), "Aligning profit and purpose through business model innovation”, in Palazzo, G. and Wentland, M. (Eds), Responsible Management Practices for the 21st Century, Pearson, Paris, pp. 61-75.

Padilla-Melendez, A., Del Aguila-Obra, A.R. and Lockett, N. (2012), "Shifting sands: regional perspectives on the role of social capital in supporting open innovation through knowledge transfer and exchange with small and medium-sized enterprises", International Small Business Journal, Vol. 31 No. 3, pp. 296-318.

Poon, S. and Swatman, P.M. (1999), "An exploratory study of small business Internet commerce issues", Information and Management, Vol. 35 No. 1, pp. 9-18.

Rao, S.S., Metts, G. and Monge, C.A.M. (2003), "Electronic commerce development in small and medium sized enterprises: a stage model and its implications", Business Process Management Journal, Vol. 9 No. 1, pp. 11-32.

Raymond, L. and Bergeron, F. (2008), "Enabling the business strategy of SMEs through e-business capabilities: a strategic alignment perspective", Industrial Management and Data Systems, Vol. 108 No. 5, pp. 577-595.

Sanders, J. and Galloway, L. (2013), "Rural small firms' website quality in transition and market economies", Journal of Small Business and Enterprise Development, Vol. 20 No. 4, pp. 788-806, doi: 10.1108/JSBED-01-2012-0009.

Schultze, U., Hiltz, S.R., Nardi, B., Rennecker, J. and Stucky, S. (2008), "Using synthetic worlds for work and learning”, Communications of the Association for Information Systems, Vol. 22 No. 1, pp. 351-370.

Spinelli, R., Dyerson, R. and Harindranath, G. (2013), "IT readiness in small firms", Journal of Small Business and Enterprise Development, Vol. 20 No. 4, pp. 807-823, doi: 10.1108/JSBED-012012-0012.

Taiminen, H.M. and Karjaluoto, H. (2015), "The usage of digital marketing channels in SMEs", Journal of Small Business and Enterprise Development, Vol. 22 No. 4, pp. 633-651, doi: 10.1108/JSBED-052013-0073.

Taylor, M. and Murphy, A. (2004), "SMEs and e-business", Journal of Small Business and Enterprise Development, Vol. 11 No. 3, pp. 280-289.

Thompson, J.D. (1967), Organization in Action, McGraw-Hill, Chicago.

Thompson, P., Williams, R. and Thomas, B. (2013), "Are UK SMEs with active web sites more likely to achieve both innovation and growth?”, Journal of Small Business and Enterprise Development, Vol. 20 No. 4, pp. 934-965, doi: 10.1108/JSBED-05-2012-0067.

van de Ven, A.H. and Poole, M.S. (1995), "Explaining development and change in organizations", The Academy of Management Review, Vol. 20 No. 3, p. 510, doi: 10.2307/258786.

Van De Ven, A.H., Delbecq, A.L. and Koenig, R. (1976), "Determinants of coordination modes within organizations", American Sociological Review, Vol. 41 No. 2, pp. 322-338.
A model for digital development of SMEs 
JSBED

27,7

1068
Vial, G. (2019), "Understanding digital transformation: a review and a research agenda", Journal of Strategic Information Systems, Vol. 28 No. 2, pp. 118-144, doi: 10.1016/j.jsis.2019.01.003.

Whitley, R. (2000), "The institutional structuring of innovation strategies: business systems, firm types and patterns of technical change in different market economies", Organization Studies, Vol. 21 No. 5, pp. 855-886, doi: 10.1177/0170840600215002.

Willcocks, L., Sauer, C. and Associates (2000), Moving to E-Business, Random House Business Books, London.

Yin, R.K. (2009), Case Study Research: Design and Methods 4e, SAGE Publications, Thousand Oaks.

Zheng, J. (2004), "Small firms and e-business: cautiousness, contingency and cost-benefit", Journal of Purchasing and Supply Management, Vol. 10 No. 1, pp. 27-39.

\section{Corresponding author}

Stefano Za can be contacted at: stefano.za@unich.it

For instructions on how to order reprints of this article, please visit our website: 